\title{
a case report
}

Antonela Sabati Rajić, dr. med., spec. int. med., Matevž Škrget, dr. med., spec. int. med., Sarah Gomezelj, med. stud.

University Medical Centre Ljubljana, Zaloška cesta 2, 1000 Ljubljana, SLOVENIA

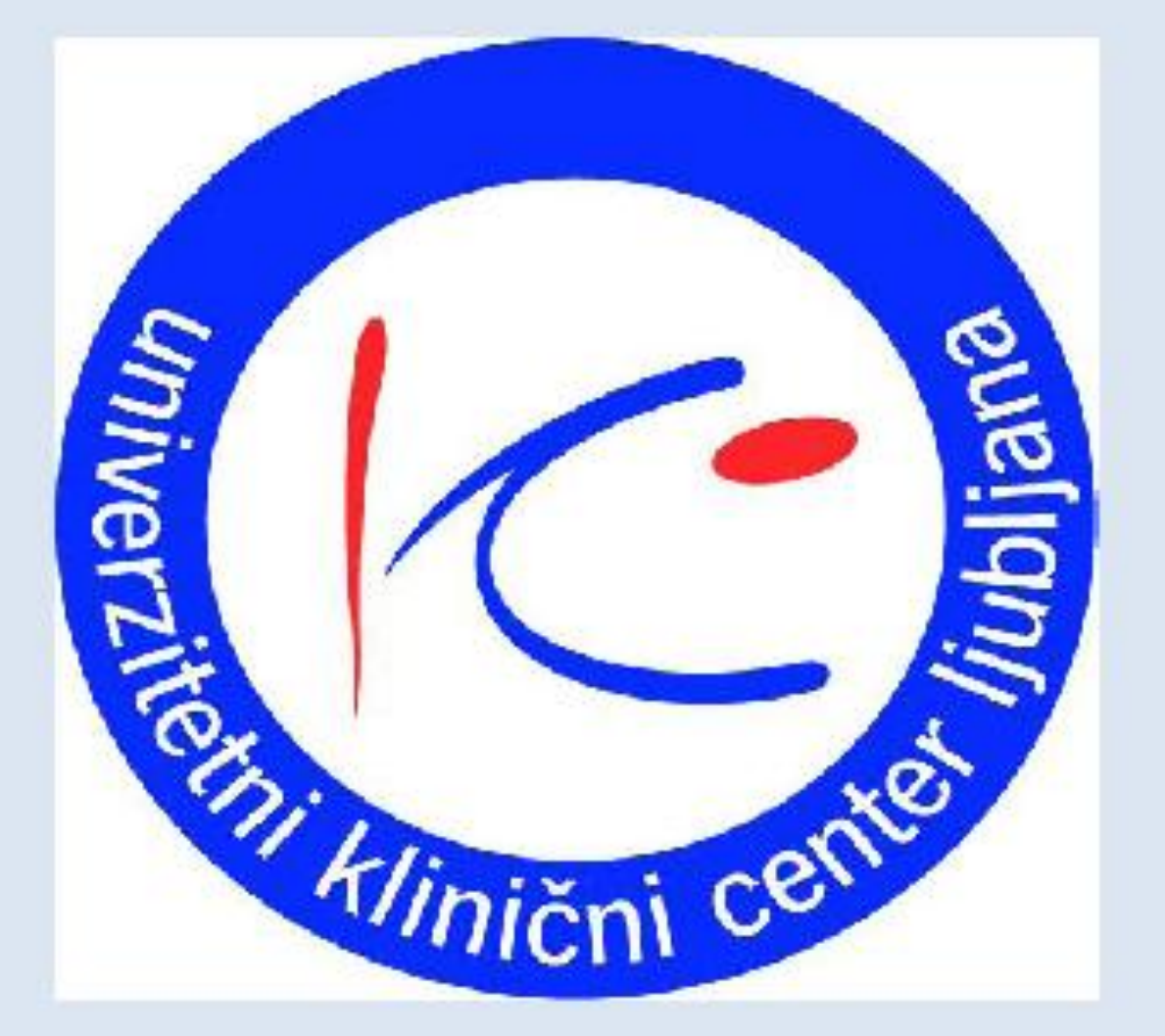

\section{CASE REPORT}

A 49-year old Caucasian male was referred to the Endocrinology department with the diagnosis of a pituitary macroadenoma. He noticed subacute diplopia on left lateral gaze with no other subjective complaints.

His family history was negative for endocrinopaties or malignancy and his medical history was positive for long-term arterial hypertension, obesity and smoking. He admitted to some fatigue, changes in his appetite, frequent back and leg pain as well as erectile dysfunction.

His physical examination was remarkable for strabismus on both forward and lef lateral gaze. Abduction of the left eye was minimal. Goldmann perimetry showed no obvious visual field defects. The initial blood parameters were unremarkable.

\begin{tabular}{|c|c|c|}
\hline & Results & Normal range \\
\hline PRL & $\mathbf{4 1 , 2} \mathbf{~ \mu g} / \mathrm{L}$ & $<17 \mu \mathrm{g} / \mathrm{L}$ (men) \\
\hline TSH & $\mathbf{1 , 5 9} \mathrm{mIE} / \mathrm{L}$ & $0,35-5,5 \mathrm{mIE} / \mathrm{L}$ \\
\hline fT4 & $\mathbf{8 , 8 7} \mathbf{~ p m o l} / \mathrm{L}$ & $11,5-22,7 \mathrm{pmol} / \mathrm{L}$ \\
\hline fT3 & $\mathbf{2 , 6 1} \mathbf{~ p m o l} / \mathrm{L}$ & $3,5-6,5 \mathrm{pmol} / \mathrm{L}$ \\
\hline Cortisol (ACTH stimulation & $0 \mathrm{~min}: 519 \mathrm{nmol} / \mathrm{L} ; 30 \mathrm{~min}:$ & ok \\
\hline test) & $577 \mathrm{nmol} / \mathrm{L}$ & $0,8-7,6 \mathrm{E} / \mathrm{L}$ \\
\hline LH & $2,26 \mathrm{E} / \mathrm{L}$ & $0,7-11,1 \mathrm{E} / \mathrm{L}$ \\
\hline FSH & $1,39 \mathrm{E} / \mathrm{L}$ & $6,7-25,7 \mathrm{nmol} / \mathrm{L}$ \\
\hline Testosterone & $\mathbf{1 , 4} \mathbf{n m o l} / \mathrm{L}$ & $64-210 \mathrm{ng} / \mathrm{mL}$
\end{tabular}

Table 1: Initial endocrinological assessment, February 2014

A subsequent MRI scan of the head, focusing on the pituitary, showed a $43 \times 60 \times$ I $45 \mathrm{~mm}$ destructive tumorous lesion. MRI was not typical for pituitary

macroadenoma and raised the possibility of another type of tumor.

A biopsy of the sphenoidal sinus mass was performed. The histological assessment of the sample gave the diagnosis of a moderately differentiated plasmacytoma with kappa light-chain restriction.

Additional blood and serum tests were performed: serum proteinogram was within the normal range but the free light chain count was high with elevated kappa chains at 93,50 mg/L. The kappa/lambda ratio was 4,72 (normal range 0,26 $-1,65)$. The level of serum beta- 2 microglobulin was also abnormal $-3,88 \mathrm{mg} / \mathrm{L}$ (normal $<2,4 \mathrm{mg} / \mathrm{L}$ ) and the urine test for Bence-Jones protein was positive. Bone marrow biopsy showed only reactive changes in the bone marrow with no cytological signs of plasmacytoma. Additional radiological imaging revealed a pathological infiltrate of the $8^{\text {th }}$ thoracic vertebra with no signs of osteolytic lesions elsewhere and the patient was therefore diagnosed with disseminated Bence Jones kappa plasmacytoma.

$\mathrm{t}$ .

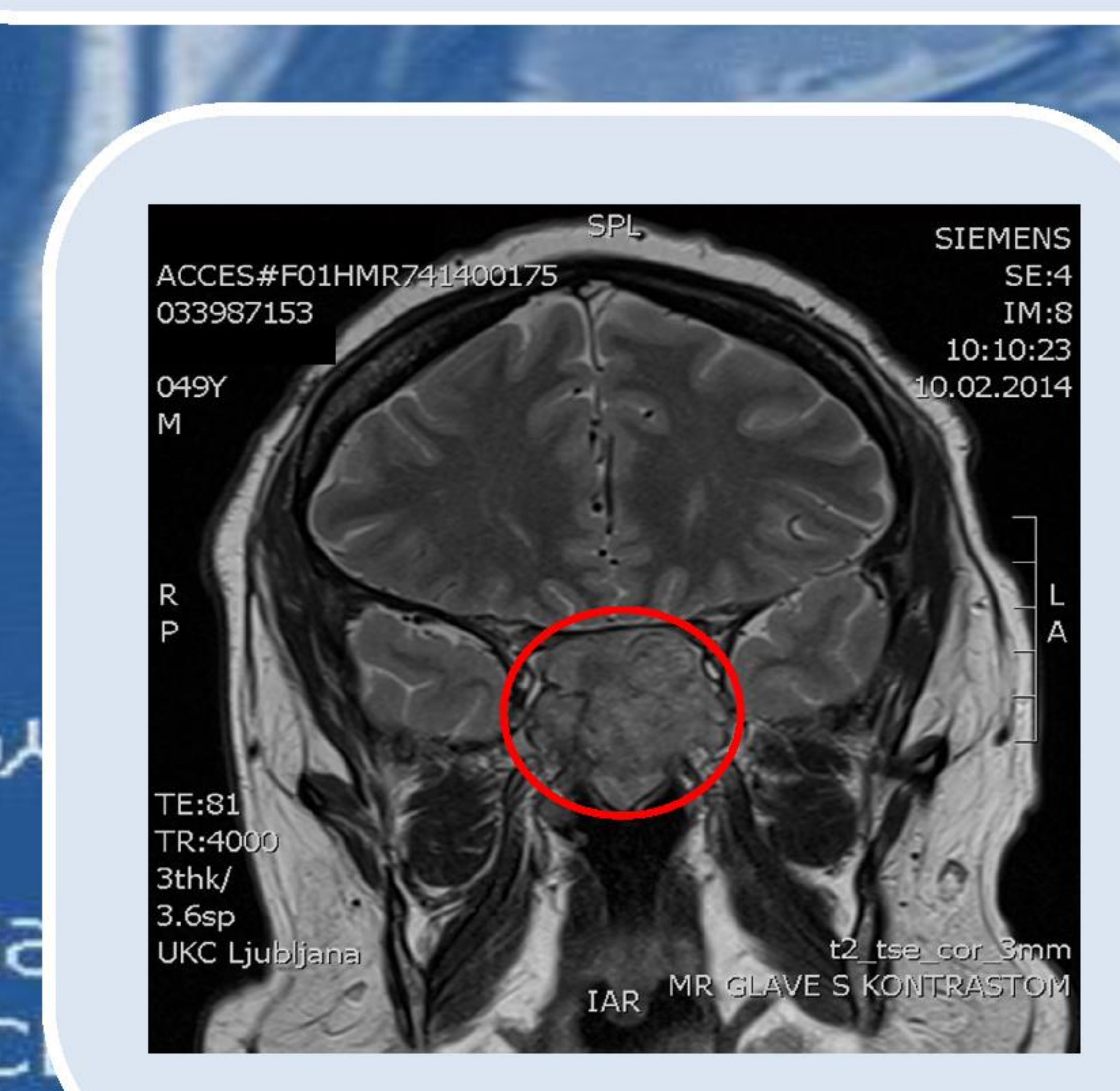

The patient was transferred to the Hematological department for commencement of treatment with bortezomib and dexamethasone as well as radiotherapy of the skull base and $8^{\text {th }}$ thoracic vertebra. During treatment, secondary adrenal insufficiency was revealed and the patient was started on hydrocortisone therapy. He has recently completed the first cycle of treatment and his last free light chain kappa level was higher than normal at 53,60 mg/L but with kappa/lambda ratio of 1,59 (normal). He is also a candidate for autologous peripheral blood stem cell transplantation, which might be attempted in second remission.

His last pituitary hormone assessment showed a normal prolactin level $(7,35 \mu \mathrm{g} / \mathrm{L})$ with appropriate thyroid and adrenal function and normal testosterone level upon substitution therapy. The control MRI scan also showed a reduction in size of the tumor mass $(21 \times 38 \times 23 \mathrm{~mm})$.

\section{REFERENCES}

[1] The international myeloma working group, "Criteria for the classification of monoclonal gammopathies, multiple myeloma and related disorders: a report of the
Journal of Haematology, no. 121, pp. 749-757, 2003. Journal of Haematology, no. 121, pp. 749-757, 2003. Clinical Neuroradiology, no. 18, pp. 5-18, 2008.

[3] I. S. Khan, V. Javalkar, J. D. Thakur and A. Nanda, "Intrasellar plasmacytoma: An illustrative case and literature review, "Journal of Clinica Neuroscience, no. 19, pp. 210-213, 2012.

[4] R. Joukhadar and K. Chiu, "Sellar plasmacytomas: a concise review," Pituitary, no. 15, pp. 146-149, 2012 [5] M. Q.-S. L. M. X.-Y. W. M. C.-Y. W. M. D.-Z. K. P. Chang-Zheng Jiang, "Sellar Solitary Plasmacytoma progressing to Multiple Myeloma: a case report and literature review," Medicine, vol. 93, no. 11, 2014. [6] D. Sautner, W. Saeger and D. Ludecke, "Tumors of the sellar region mimicking pituitary adenomas," Experimental Clinical Endocrinology \& Diabetes, no. 101, pp. 283-289, 1993. [7] J. Sanchez, S. Rahman, S. RA and G. Kaye, "Multiple myeloma
of Pathology and Laboratory Medicine, no. 101, pp. 55-56, 1977. [8] A. Silverstein and D. Doniger, "Neurologic complications of myelomatosis," Archives of Neurology, no. 9, pp. 534-544, 1963. 